\title{
Failure of IGF-I and IGFBP-3 to diagnose growth hormone insufficiency
}

\author{
H Mitchell, M T Dattani, V Nanduri, P C Hindmarsh, M A Preece, C G D Brook
}

\begin{abstract}
Background-Growth hormone insufficiency (GHI) is diagnosed conventionally by short stature and slow growth, and is confirmed by diminished peak GH response to a provocation test. Insulin-like growth factor I (IGF-I) and IGF binding protein 3 (IGFBP-3) have previously been considered individually

Objective-To test the hypothesis that the combined analysis of IGF-I and IGFBP-3 could act as a surrogate marker for the diagnosis of GHI.

Design-Reference ranges for IGF-I and IGFBP-3 were calculated using 521 normal individuals. A retrospective analysis was performed on 318 children referred for investigation of short stature.

Results-No significant difference was found between either the IGF-I or IGFBP-3 standard deviation scores (SDSs) in children with and without GHI. If the requirement were for both tests to be positive (<-2 SDS) for a diagnosis of GHI, then $99 \%$ of children without GHI would be correctly identified; however, the sensitivity of the test was only $15 \%$.

Conclusions-Neither IGF-I nor IGFBP-3 alone is a marker for GHI. In addition, they cannot be used as an effective screening test in combination. (Arch Dis Child 1999;80:443-447)
\end{abstract}

Keywords: insulin-like growth factor I; insulin-like growth factor binding protein 3 ; growth hormone insufficiency

Short stature is a common problem in paediatric practice and although idiopathic growth hormone insufficiency (GHI) is relatively rare (prevalence, 1/3000), ${ }^{1}$ it deserves consideration because effective therapeutic intervention is available. GHI is a heterogeneous condition. Its diagnosis is suggested by short stature and impaired height velocity but to establish the diagnosis GH secretion must be shown to be abnormal.

Human GH secretion is pulsatile. To make a diagnosis of GHI, GH secretion can be measured by means of a 24 hour profile. This is time consuming and expensive to perform and hence the diagnosis is based conventionally upon the peak $\mathrm{GH}$ response to provocation tests, which are not themselves without danger. ${ }^{2}$

Insulin-like growth factor I (IGF-I) is a well characterised peptide, the product of the interaction between $\mathrm{GH}$ and its receptor. It binds avidly to specific binding proteins (IGFBPs) with only about $1 \%$ of the circulating IGF-I present in its free form. ${ }^{3}$ Nutritional status, ${ }^{45}$ and thyroid hormones also influence the levels of circulating IGF-I. ${ }^{6}$

When a specific radioimmunoassay was first developed for IGF-I, ${ }^{7}$ early results suggested that IGF-I might be used in screening for GHI. ${ }^{8}$ However subsequent researchers have found it to be a poor diagnostic marker. ${ }^{9}$

IGFBP-3 was proposed as an alternative surrogate marker for GHI because its serum concentration is also closely related to $\mathrm{GH}$ secretory status. ${ }^{10}{ }^{11}$ IGFBP-3 binds to IGF-I and associates with an acid labile subunit to form a high molecular weight ternary complex. ${ }^{12}$ However, IGFBP-3 alone has a poor sensitivity in detecting patients with GHI and offers no diagnostic advantage over IGF-I. ${ }^{13}$

We aimed to test the hypothesis that the combined analysis of serum measurements of IGF-I and IGFBP-3 could act as a surrogate marker for the diagnosis of GHI.

\section{Materials and methods}

DATA COLLECTION

We measured concentrations of IGF-I and IGFBP-3 on the serum samples of 281 normal male subjects (aged 0.05 to 69.9 years) and 240 female subjects (aged 0.01 to 74.2 years). They had been recruited as normal controls in other research studies and their heights were between the third and 97th centiles on the Tanner and Whitehouse growth charts.

We took blood for the measurement of serum IGF-I and IGFBP-3 from 318 children and young adults (184 boys, aged 1.7 to 25.4 years: 134 girls, aged 0.9 to 19.9 years). They were referred consecutively for GH provocation tests to the London centre for paediatric endocrinology based at Great Ormond Street Hospital (glucagon tests $10 \mu \mathrm{g} /$ $\mathrm{kg}$ ) and the Middlesex Hospital (insulin tolerance tests, $0.1-0.15 \mathrm{IU} / \mathrm{kg}$ ). We also performed auxological measurements on these patients.

ASSAYS

We measured serum IGF-I using an in-house radioimmunoassay (RIA) with acid/ethanol extraction. The sensitivity of the assay was $13 \mathrm{ng} / \mathrm{ml}$. The intra-assay coefficients of variation (CVs) were $9.0 \%, 5 \%$, and $4.7 \%$ at concentrations of 45,243 , and $698 \mathrm{ng} / \mathrm{ml}$, respectively. The interassay CVs were $10.5 \%$, $10.1 \%$, and $5.1 \%$ at concentrations of 75,196 , and $698 \mathrm{ng} / \mathrm{ml}$, respectively.

We measured serum IGFBP-3 using an immunoradiometric assay (IRMA; DSL Webster, Texas, USA). The sensitivity of the assay 
was $0.5 \mathrm{ng} / \mathrm{ml}$. The intra-assay CVs were $3.8 \%$, $3.2 \%$, and $1.8 \%$ at concentrations of 7.35 , 27.53 , and $82.72 \mathrm{ng} / \mathrm{ml}$, respectively. The interassay CVs were $0.6 \%, 0.5 \%$, and $1.9 \%$ at concentrations of $8.03,21.51$, and $76.9 \mathrm{ng} / \mathrm{ml}$, respectively.

GH was measured by the NETRIA and HYBRITRECH immunoassays at Great Ormond Street and the Middlesex Hospitals, respectively. The NETRIA assay is a solid phase IRMA based on reagents from the North East Thames region immunoassay service and has a lower limit of detection of $0.1 \mathrm{mU} / 1$. The intraassay CVs were $5.1 \%, 2.4 \%$, and $2.6 \%$ at concentrations of $0.8,4.5$, and $86.5 \mathrm{mU} / 1$, respectively. The interassay CVs were $3.3 \%, 5.2 \%$, and $5.5 \%$ at concentrations of $7.7,21.7$, and $45.8 \mathrm{mU} / 1$ respectively. The HYBRITECH assay (Hybritech Europe, Liege, Belgium) is also a solid phase IRMA, which is specific for the $22 \mathrm{kDa}$ GH fragment and has a lower limit of detection of $0.5 \mathrm{mU} / 1$. The intra-assay CVs were $10.6 \%, 5.2 \%$, and $4.9 \%$ at concentrations of $1.4,3.5$, and $14.4 \mathrm{mU} / 1$, respectively. The interassay CVs were $10.5 \%, 7.2 \%$, and $5.4 \%$ at concentrations of $6.0,13.2$, and $33.3 \mathrm{mU} / 1$, respectively. ${ }^{14}$

STATISTICAL ANALYSIS

Using the data obtained on the normal subjects, we were able to plot centiles for IGF-I and IGFBP-3 in boys/men and girls/women. We used exponentially damped polynomials to describe changes in the median, spread, and skewness. We used maximum likelihood estimation to determine the most appropriate models and to test for any significant sex effect. Hence, we expressed centiles parametrically and this allowed relatively simple estimation of age and sex adjusted standard deviation scores (SDSs). ${ }^{15} 16$

Initially, we considered the short children by dividing them into two groups based upon their peak GH response to a provocation test.

Group I: growth hormone insufficient (GHI: boys, 92 ; girls, 56 ).

Group II: non-growth hormone insufficient (non-GHI: boys, 85; girls, 73).

The groups were defined in our study using previously determined GH cut off values specific to the assay in use. In patients undergoing an insulin tolerance test, a cut off value of $13.5 \mathrm{mU} / 1$ had been determined for the peak GH response measured by the HYBRITECH assay, below which a diagnosis of GHI could be made. ${ }^{17}$ Using a similar critical appraisal of the performance characteristics of the NETRIA assay, the cut off value for a peak $\mathrm{GH}$ response to a glucagon test was determined at $35 \mathrm{mU} / 1 .^{18}$ Other investigators using different $\mathrm{GH}$ assays and provocation tests have arrived at other values for the cut off points. In our study, the large differences between the values in the NETRIA and HYBRITECH assays might be related to the designs of the immunoassays. The NETRIA assay uses polyclonal/monoclonal antibodies compared with the HYBRITECH assay, which uses a monoclonal antibody with high specificity to the $22 \mathrm{kDa} \mathrm{GH}$ isoform. When these two assays have been compared, the NETRIA assay has been shown to give higher readings for a specific quantity of $\mathrm{GH} .^{14}$

It is well recognised that $\mathrm{GH}$ provocation tests, rather than being the ideal "gold standard", have a high rate of false positives. For this reason, we also considered the prepubertal children according to another parameter suggestive of GHI, namely annualised height velocity standard deviation scores (HVSDSs), to determine whether a similar relation to IGF-I and IGFBP-3 would be seen.

Therefore, we divided prepubertal children into two groups.

Group III: short normals with HVSDS $>-0.8$ (boys, 33; girls, 28).

Group IV: short, slowly growing with HVSDS $<-0.8$ (boys, 99; girls, 51).

We used the SPSS statistical package to perform the data analyses. Correlations were calculated using the Spearman test for nonparametric data.

\section{Results}

NORMAL RANGES

Normal ranges for IGF-I (fig $1 \mathrm{~A}$ and $\mathrm{B}$ ) and IGFBP-3 (fig 1C and D) were constructed from the values obtained for the 521 normal subjects (boys/men, 281; girls/women, 240) aged from 0.01 to 74.2 years. In these individuals the IGF-I and IGFBP-3 values were both age and sex dependent. Peak values occurred at puberty and were followed subsequently by a decline, although the decline was less noticeable in IGFBP-3 than in IGF-I.

RELATION OF GH SECRETION AND HEIGHT VELOCITIES TO IGF-I AND IGFBP-3

Using these age related normal ranges for IGF-I and IGFBP-3, we converted the values for IGF-I and IGFBP-3 obtained from the children under investigation for short stature to SDS values. Figure $2 \mathrm{~A}$ shows a plot of the IGF-I SDS values obtained from GHI and non-GHI group. The prepubertal and pubertal children were analysed separately. The IGF-I concentrations were low in all short children (IGF-I SDS < 0) and, although there was a tendency for lower values to occur in the pubertal children with GHI, we could not distinguish between individuals with and without GHI in either the prepubertal or pubertal age range.

Figure $2 \mathrm{~B}$ shows the results for IGFBP-3. The IGFBP-3 SDS values show a more even distribution around the mean, but again we could not distinguish between children with and without GHI.

In the prepubertal children, we also analysed the IGF-I and IGFBP-3 SDS values based on their annualised height velocity SDS. Figure $2 \mathrm{C}$ and D shows the IGF-I and IGFBP-3 SDS values, respectively, in children with HVSDS $>-0.8$ (short normals) and HVSDS $<-0.8$ (short slowly growing). Again, we found no significant differences between the two groups, showing that similar results occur regardless of 

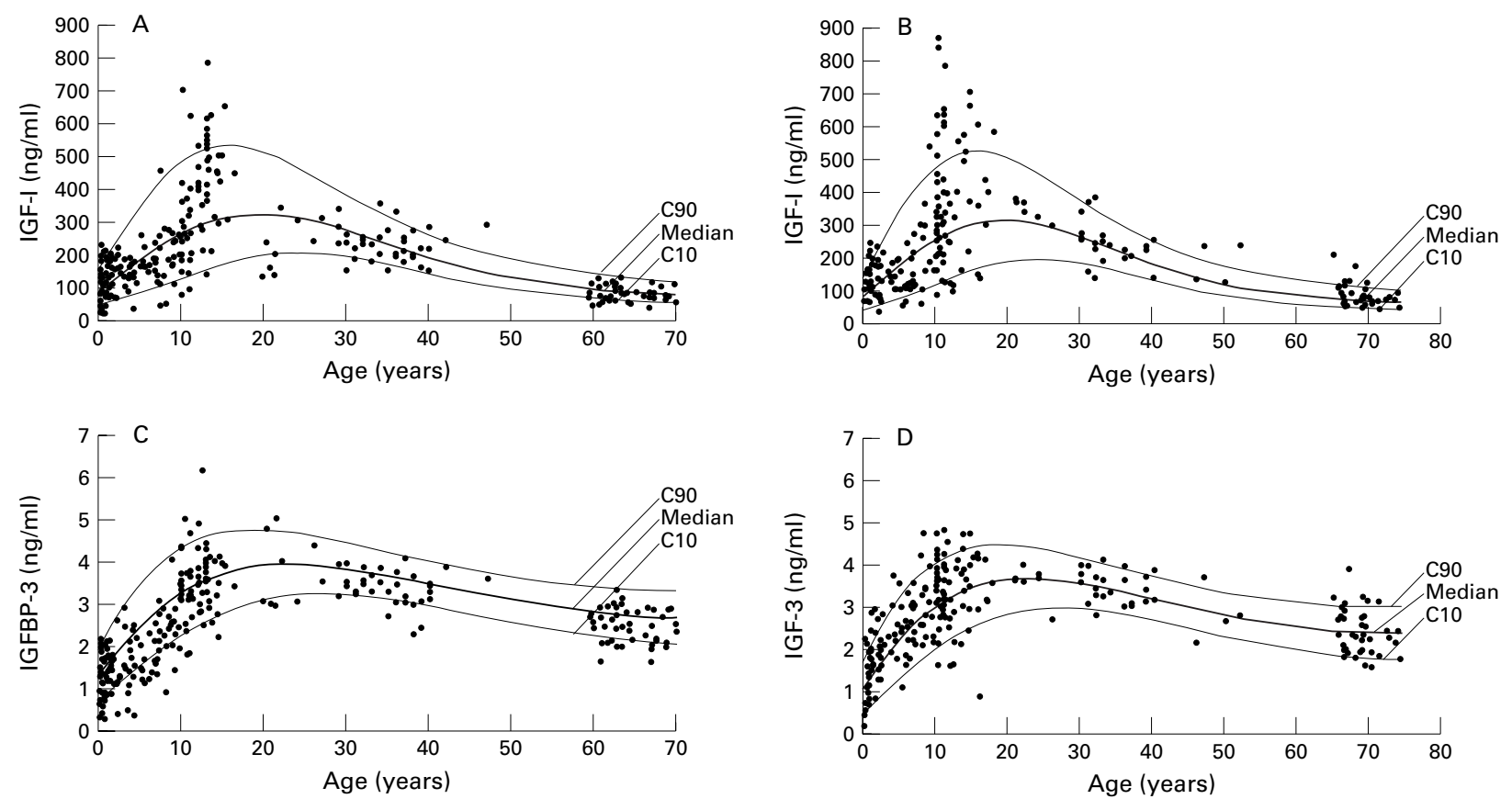

Figure 1 Insulin-like growth factor I (IGF-I) concentrations were plotted according to age, from birth to the 7 th decade of life, in normal boys/men (A) and girls/women (B). IGF binding protein 3 (IGFBP-3) concentrations were plotted according to age, from birth to the 7 th decade of life, in boys/men (C) and girls/women (D). Centile lines (C10 (10th centile), median, and C90 (90th centile)) were calculated from these data and superimposed on the real values.
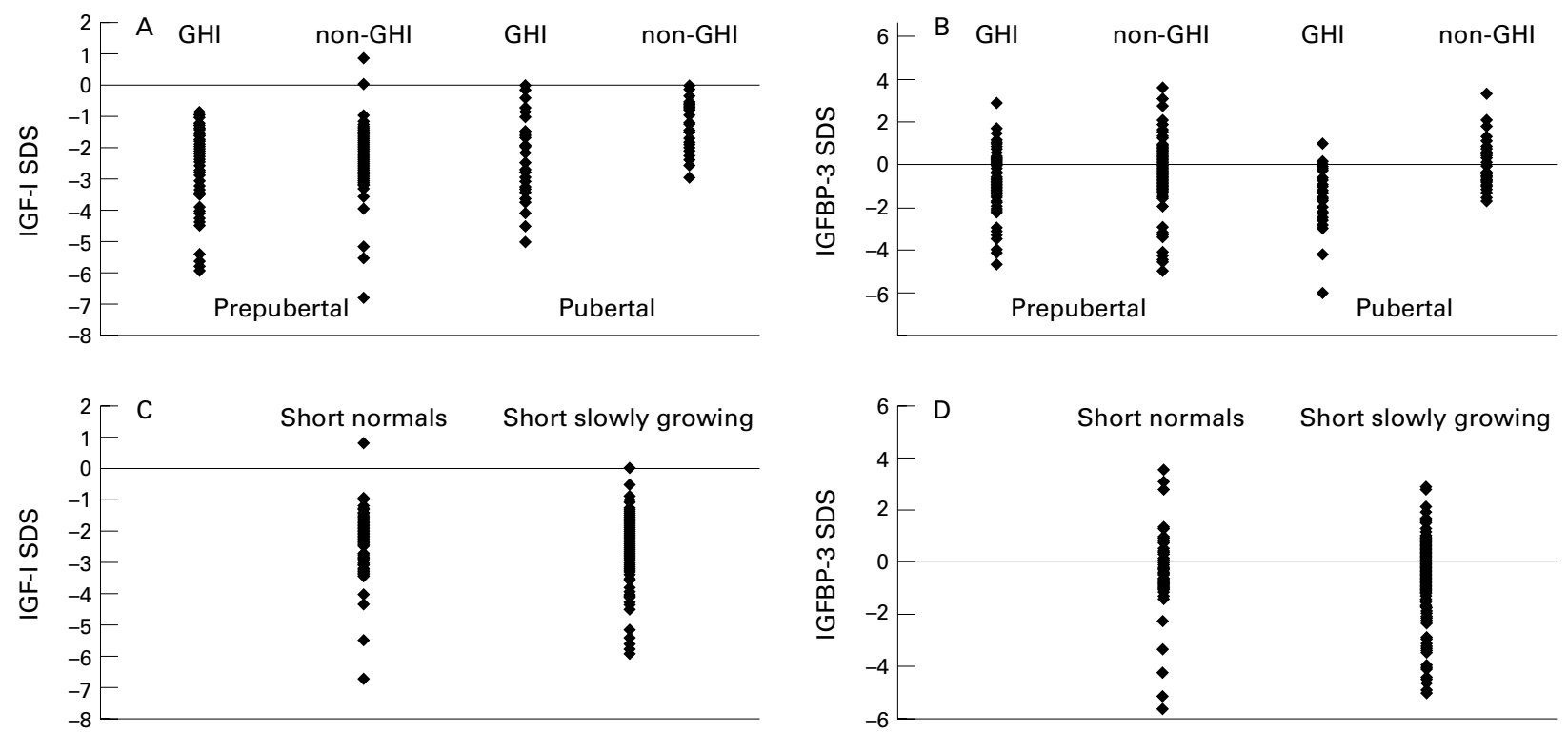

Figure 2 Serum insulin-like growth factor I (IGF-I) and IGF binding protein 3 (IGFBP-3) measurements obtained for the children investigated for short stature were converted to standard deviation scores (SDSs) using the age related normal ranges. The children were divided initially into two groups according to their pubertal status. For both the prepubertal and pubertal groups IGF-1 SDS (A) and IGFBP-3 SDS values (B) were compared in the growth hormone insufficient (GHI) and non-GHI groups, defined according to the previously described cut off values. In the prepubertal children, the IGF-I SDS (C) and IGFBP-3 SDS values (D) were also compared according to the children's annualised height velocity (HVSDS): short normals HVSDS > -0.8; short slowly growing HVSDS < -0.8.

whether height velocity or peak $\mathrm{GH}$ values are used to discriminate between the children.

EVALUATION OF IGF-I AND IGFBP-3 “CUT OFFS" FOR THE DIAGNOSIS OF GHI

Using the $\mathrm{GH}$ peaks in response to provocation tests as the gold standard method for the diagnosis of GHI, we assessed various cut off points for the IGF-I SDS and IGFBP-3 SDS in terms of their efficiency, sensitivity, and specificity as a single test measurement ${ }^{19}{ }^{20}$ (table 1).
When considering IGF-I SDS, the sensitivity of the test reached a figure of $62 \%$ at best, with an efficacy of $55 \%$ at a cut off value of -2 SDS. However, the specificity of the test was only $47 \%$, so using a -2 SDS cut off, a large proportion of children with normal $\mathrm{GH}$ values on provocation would be misdiagnosed as being GH insufficient. Similarly with IGFBP-3, the best compromise was a cut off point of -0.5 SDS, with a sensitivity of $61 \%$, a specificity of $68 \%$, and an efficiency of $65 \%$. 
Table 1 Comparison of the sensitivities, specificities, and efficiencies of insulin-like growth factor I (IGF-I) and IGF binding protein 3 (IGFBP-3) measurements at different cut off SDS values

\begin{tabular}{|c|c|c|c|c|c|c|}
\hline \multirow{2}{*}{$\begin{array}{l}\text { Cut off } \\
\text { SDS }\end{array}$} & \multicolumn{3}{|l|}{$I G F-1$} & \multicolumn{3}{|l|}{$I G F B P-3$} \\
\hline & Sensitivity & Specificity & Efficiency & Sensitivity & Specificity & Efficiency \\
\hline-5 & 1.7 & 100 & 48 & & & \\
\hline-4 & 10.3 & 99 & 53 & & & \\
\hline-3 & 28 & 91 & 58 & 2.6 & 99 & 48.6 \\
\hline-2 & 62 & 47 & 55 & 14.9 & 98 & 54.6 \\
\hline-1 & 95 & 11.6 & 54 & 49 & 83.6 & 65.5 \\
\hline-0.5 & & & & 61 & 68 & 64.6 \\
\hline
\end{tabular}

Table 2 Both tests required to be negative to identify children without growth hormone insufficiency (GHI)

\begin{tabular}{lll}
\hline & $\begin{array}{l}\text { Non-GHI } \\
\text { group }\end{array}$ & $\begin{array}{l}\text { GHI } \\
\text { group }\end{array}$ \\
\hline Both tests negative & 80 & 50 \\
One or both tests positive & 68 & 87 \\
\hline
\end{tabular}

Sensitivity, $54 \%$, specificity, $64 \%$.

Table 3 Both tests required to be positive to diagnose growth hormone insufficiency (GHI)

\begin{tabular}{lcc}
\hline & $\begin{array}{l}\text { GHI } \\
\text { group }\end{array}$ & $\begin{array}{l}\text { Non-GHI } \\
\text { group }\end{array}$ \\
\hline Both tests positive & 21 & 2 \\
One or both tests negative & 116 & 146 \\
\hline
\end{tabular}

Sensitivity, $15 \%$, specificity, $99 \%$.

EVALUATION OF A COMBINATION OF IGF-I AND IGFBP-3 TESTS

Both tests required to be negative to identify non-GHI children

The IGF-1 and IGFBP-3 data were analysed according to the approach used by Sackett et $a l{ }^{21}$ The first hypothesis used was the requirement for both tests to be negative (normal) to identify the non-GHI children (table 2). A negative test was defined as one in which the IGF-I or IGFBP-3 SDS values were > -2 SDS from the mean. However, the sensitivity of this combined test is only $54 \%$ and the specificity $64 \%$. Hence, $46 \%$ of the normal children would be misdiagnosed as children with GHI.

Both tests required to be positive to diagnose GHI The second hypothesis used was the requirement for both tests to be positive (abnormal) to make the diagnosis of GHI (table 3 ). A positive test was defined as an IGF-I or IGFBP-3 SDS of $<-2$ SDS below the mean. Thus, $99 \%$ of children without GHI would be correctly identified. However, with a sensitivity of only $15 \%$, $85 \%$ of children who are currently diagnosed as GHI on provocation testing would be missed. We note that if both tests were abnormal a child is highly likely to have GHI.

\section{Discussion}

Our data collected on the serum IGF-I and IGFBP-3 measurements in the control subjects of normal height (third to 97 th centile) agreed with those reported by others. ${ }^{1322-24}$ We found both IGF-I and IGFBP-3 to be highly age dependent. We were interested to note that, although both IGF-I and IGFBP-3 are GH dependent, there is much less of a decline in IGFBP-3 than IGF-I after puberty. This might reflect the influence of other factors present in the circulation causing an uncoupling of
IGFBP-3 from its direct relation to the GH response. We found IGF-I concentrations to be below the mean in all short children, although there was a tendency for IGF-I concentrations to be lower in the GHI group. However, there was considerable overlap between the children with GHI and those diagnosed as having idiopathic short stature, making it impossible to discriminate between the two groups. This agrees with other published data. ${ }^{6}$ Similar patterns of results were obtained regardless of whether the growth failure was defined according to clinical parameters, such as growth velocity, or the gold standard GH concentrations after provocation testing. Others have concluded that IGF-I is a poor discriminator in young children. ${ }^{23}$ However, in our study population the IGF-I concentrations were low in all short children irrespective of age.

IGF-I is related to GH secretion but the question remains as to why this association is weak when short children are considered on an individual basis. This is probably because of factors other than GH that influence the IGF-I concentration. Some of these are well recognised-namely, nutrition-but other influences are not so clearly defined.

Similarly the IGFBP-3 measurements did not discriminate between the children with GHI and those with a diagnosis of idiopathic short stature, as had been demonstrated previously. ${ }^{13}$ However, in contrast to IGF-I, IGFBP-3 concentrations were not low in all short children and little is known at present about factors that may influence the uncoupling of this protein from the $\mathrm{GH}$ response.

Others have considered the diagnostic roles of the IGFs as molar ratios in serum and concluded that the best measurement for differentiating GHI was the IGF-I: IGF-II ratio. ${ }^{25}$ Furthermore, the diagnostic roles of urinary IGF-I and IGFBP-3 concentrations have been considered. However, near complete overlap was seen between children with GHI and short normal children. ${ }^{26}$

We conclude that, at present, there is no easily measured and well defined serum marker for diagnosing GHI. Neither IGF-I nor IGFBP-3 alone is a surrogate marker for GHI and even when analysed in combination they cannot be used as an effective screening test.

Perhaps in the future we will focus more on the components of $\mathrm{GH}$ in the circulation. $\mathrm{GH}$ is present as a number of differently sized isoforms and current assay techniques primarily measure the presence of the $22 \mathrm{kDa}$ fragment. With the development of assays specific for other isoforms, we can attempt to analyse the relative importance of these to growth in vivo. In addition, we need to consider a spectrum of partial end organ resistance to $\mathrm{GH}$ or variation in the biological activity of GH itself.

H Mitchell is a Smith and Nephew Medical Research Fellow. We thank Dr AM Wade, Institute of Child Health, London, for performing the statistical analysis of the normal data and creating the IGF-I and IGFBP-3 centiles; Mrs J Jones, Kings College Hospital for performing the IGF-I/IGFBP-3 assays; Ms J PrinHospital for performing the IGF-I/IGFBP-3 assays; Ms
gle and Mrs B Leonard, Cobbold Laboratories, The Middlesex gle and Mrs B Leonard, Cobbold Laboratories, The Middlesex
Hospital for performing the Hybritech GH assays; and Dr A Hospital for performing the Hybritech GH assays; and Dr A
Winrow, Kingston Hospital for providing the normal adolescent Winrow, Kingsto
control samples. 
1 Lindsay R, FeldKamp M, Harris D, Robertson J, Rallison M. Utah growth study: growth standards and the prevalence of growth hormone deficiency $f$ Pediat 1994;125:29-35.

2 Shah A, Stanhope R, Matthews D. Hazards of pharmacological tests of growth hormone in childhood. $B M \mathcal{F}$ 1992;304:173-4

3 Baxter RC. Circulating binding proteins for the insulin-like growth factors. Topics in Endocrinology and Metabolism 1993;4:91-6.

4 Isley WL, Underwood LE, Clemmons DR. Dietary components that regulate serum somatomedin-C concentrations in humans. $\mathcal{F}$ Clin Invest 1983;71:175-82.

5 Rasmussen MH, Frystyk J, Andersen T, et al. The impact of obesity, fat distribution and energy restriction on insulinlike growth factor-I (IGF-I), IGF-binding protein-3, insulin and growth hormone. Metabolism 1994:3:315-19.

6 Rosenfeld RG, Wilson DM, Lee PDK, Hintz RL. Insulin-like growth factors I and II in evaluation of growth Insulin-like growth factors 1 and II in eval

7 Furlanetto RW, Underwood LE, Van Wyk JJ, D'ercole AJ. Estimation of somatomedin-C levels in normals and Estimation of somatomedin-C levels in normals and patients with pituitary dise
Invest $1977 ; 60: 648-57$

8 Blum WF, Ranke MB, Kietzmann K, Gauggel E, Zeisel HJ, Bierech JR. A specific radioimmunoassay for the growth hormone $(\mathrm{GH})$-dependent somatomedin-binding protein: its use for diagnosis of $\mathrm{GH}$ deficiency. $\mathcal{F}$ Clin Endocrinol Metab 1990;70:1292-8.

9 Ada L, Souberbielle JC, Brauner R. Diagnostic markers of permanent idiopathic growth hormone deficiency. 7 Clin Endocrinol Metab 1994;78:353-8.

10 Blum WF, Albertsson K, Wikland, Rosberg S, Ranke MB. Serum levels of insulin-like growth factor-I (IGF-I) and IGF binding protein-3 reflect spontaneous growth hormone secretion. 7 Clin Endocrinol Metab 1993;76:1610-16.

11 Hasegawa Y, Hasegawa T, Yokoyama T, Kotoh S, Tsuchiya Y, Kurimoto F. Western ligand blot assay for human growth hormone-dependent insulin-like growth factor binding protein (IGFBP3): the serum levels in patients with classical growth hormone deficiency. Endocrinol fpn 1992;39: cal grow

12 Baxter RC, Martin JL. Structure of the Mr 140,000 growth hormone dependent insulin-like growth factor binding protein complex: determination by reconstitution and affinity-labeling. Proc Natl Acad Sci USA 1989;86:6898902
13 Cianfarani S, Boemi S, Spagnoli A, et al. Is IGF binding protein-3 assessment helpful for the diagnosis of $\mathrm{GH}$ defiprotein-3 assessment helpful for the diagnosis

14 Pringle PJ, Jones J, Hindmarsh PC, Preece MA, Brook CGD. Performance of proficiency survey samples in two immunoradiometric assays of human growth hormone and comparison with patients' samples. Clin Chem 1992;38: 553-7.

15 Cole TJ. The LMS method for constructing normalized growth standards. Eur f Clin Nutr 1990;44:45-60.

16 Wade AM, Ades AE. Age-related reference ranges: significance tests for models and confidence intervals for centiles. Stat Med 1994;13:2239-367.

17 Dattani MT, Pringle PJ, Hindmarsh PC, Brook CGD. What is a normal stimulated growth hormone concentration? $f$ Endocrinol 1992;133:447-50.

18 Nanduri V, Davies H, Jones J, et al. Diagnosis of growth hormone (GH) deficiency - a conundrum. Horm Res 1996; 46(suppl 2):1-35.

19 Sox HC. The evaluation of diagnostic tests: principles, problems and new developments. Anпu Rev Med 1996;47: $463-71$

20 Sox HC. Probability theory in the use of diagnotic tests. Ann Intern Med 1986;104:60-6.

21 Sackett DL, Haynes RB, Guyatt GH, Tugwell P. Clinical epidemiology: a basic science for clinical medicine. 2nd ed. Boston: Little, Brown \& Co, 1991.

22 Juul A, Holm K, Kastrup KW, et al. Free insulin-like growth factor I serum levels in 1430 healthy children and adults, and its diagnostic value in patients suspected of growth hormone deficiency. F Clin Endocrinol Metab 1997;82: 2497-502.

23 Rasat R, Livesey JL, Espiner EA, Abbot GD, Donald RA. IGF-I and IGFBP-3 screening for disorders of growth hormone secretion. NZ Med F 1996;109:156-9.

24 Tillman V, Buckler JMH, Kilbridge MS, et al. Biochemical tests in the diagnosis of childhood growth hormone deficiency. 7 Clin Endocrinol Metab 1997;82:531-5.

25 Rikken B, van Doorn J, Ringeling A, Van den Brande JL, Massa G, Wit JM. Plasma levels of insulin-like growth factor (IGF) -I, IGF-II and IGF-binding protein-3 in the evaluation of childhood growth hormone deficiency. Horm Res 1998;50:166-76.

26 Gill MS, Whatmore AJ, Tillman V, et al. Urinary IGF and IGF binding protein-3 in children with disordered growth. Clin Endocrinol (Oxf) 1997;46:483-92. 